\title{
Músculos del piso de boca en TEM vs. IRM
}

\author{
Mouth floor muscles in TEM vs. IRM
}

Kevin Roberto Romero Díaz ${ }^{\text {1a,2b }}$, Abell Sovero Gaspar ${ }^{2, c}$, Fredy Gutiérrez Ventura ${ }^{2, d}$

\section{RESUMEN}

El presente artículo de revisión fue realizado para comparar detalles imagenológicos de resonancia magnética y tomografía espiral multicorte de las estructuras anatómicas del piso de boca; esta es una región desafiante de la cavidad oral para el odontólogo ya que se encuentra constituida de tejidos blandos, vasculares, glandulares y nerviosos, a su vez carece de tejidos óseos volviéndola mucho más susceptible a patologías. Por ello la resonancia magnética es el estudio de preferencia para los tejidos blandos pues permite conocer con más facilidad la anatomía y a la tomografía espiral multicorte ideal para el análisis de tejidos duros, sin embargo puede evaluarse el piso de boca sin ser el estudio imagenológico indicado para esta. El presente trabajo es una recopilación de artículos en bases de datos e internet con el fin de comparar detalles imagenológicos entre la resonancia magnética y tomografía espiral multicorte.

PALABRAS ClAVE: Resonancia magnética, Tomografía espiral multicorte, piso de boca, anatomía, músculos.

\section{SUMMARY}

This review article was conducted to compare magnetic resonance imaging and multislice spiral tomography of floor of mouth anatomical structures; this is a challenging region of oral cavity for dentist since it is made up of soft, vascular, glandular and nervous tissues, in turn lacks bone tissues, making it much more susceptible to pathologies. Therefore, magnetic resonance is the preference study for soft tissues because it allows knowing more easily anatomy and multislice spiral tomography ideal for hard tissues analysis, however floor of mouth can be evaluated without being the imaging study indicated for is. The present work is a compilation of articles in databases and internet in order to compare both: magnetic resonance and multislice spiral tomography.

KEYWORDS: Magnetic resonance, multislice spiral tomography, floor of mouth, anatomy, muscles.

Facultad de Odontología, Universidad Estatal de Guayaquil. Guayaqui, Ecuador

Facultad de Estomatología Roberto Beltrán, Universidad Peruana Cayetano Heredia. Lima, Perú.

Cirujano Dentista

Residente de la Especialidad de Radiología Bucal y Maxilofacial

Especialista en Radiología Oral y Maxilofacial.

Especialista Cirugía Bucal y Maxilofacial - Ortodoncia 


\section{INTRODUCCIÓN}

El piso de la boca es la parte de la cavidad oral que se encuentra debajo de la lengua, un área desafiante para el diagnóstico radiológico. Los tejidos blandos, las estructuras glandulares y las relaciones óseas se encuentran en estrecha proximidad y se requiere una comprensión sólida de la anatomía radiológica, pueden estar involucrados en una amplia gama de procesos patológicos, algunos de los cuales son exclusivos de la región. La superficie de la mucosa del piso de la boca se examina fácilmente clínicamente, ya que las anomalías superficiales se pueden evaluar visualmente sin la ayuda de imágenes. Sin embargo, las imágenes pueden ser necesarias para evaluar la enfermedad que se extiende hacia el fondo de la boca o hacia sus límites.

La imagen de la cavidad oral puede estar limitada por artefactos de la amalgama dental y superficies de la mucosa; sin embargo, los protocolos de imágenes pueden adaptarse a la presentación específica del paciente utilizando una combinación de TC, IRM.

\section{Anatomía del piso de boca}

La cavidad oral es un área desafiante en imágenes de cabeza y cuello debido a su anatomía compleja y las numerosas fisiopatologías que involucran sus con- tenidos. Los músculos clave asociados con la cavidad oral incluyen el vientre anterior del digástrico, milohioideo, geniogloso, geniohioideo e hiogloso. El vientre anterior del digástrico se halla en el espacio submentoniano $(1,2)$.

El músculo milohioideo divide los espacios submandibular y sublingual; el geniogloso y el geniohioideo están en la raíz de la lengua, y el músculo hiogloso está en el espacio sublingual $(3,4)$.

Sin embargo, las imágenes pueden ser necesarias para evaluar la enfermedad que se extiende profundamente en el piso de la boca o se extiende más allá de sus límites. Se pueden aplicar diversas modalidades de imágenes para examinar el piso de la boca (5).

La TEM y la IRM son complementarias en la evaluación de la cavidad oral. Las ventajas de la TC incluyen una mejor accesibilidad, un tiempo de adquisición más rápido y una mejor evaluación del hueso cortical. Las ventajas de IRM incluyen ninguna radiación ionizante, una mejor caracterización de la extensión del tumor local, una mejor evaluación de la participación de la médula ósea y la detección de la extensión perineural $(6,7)$ (figuras 1,2,3,4,5,6,7,8,9,10,11,y 12). El músculo milohioideo separa el piso de la boca de los espacios submandibulares derecho e izquierdo y el espacio submental de la línea media.
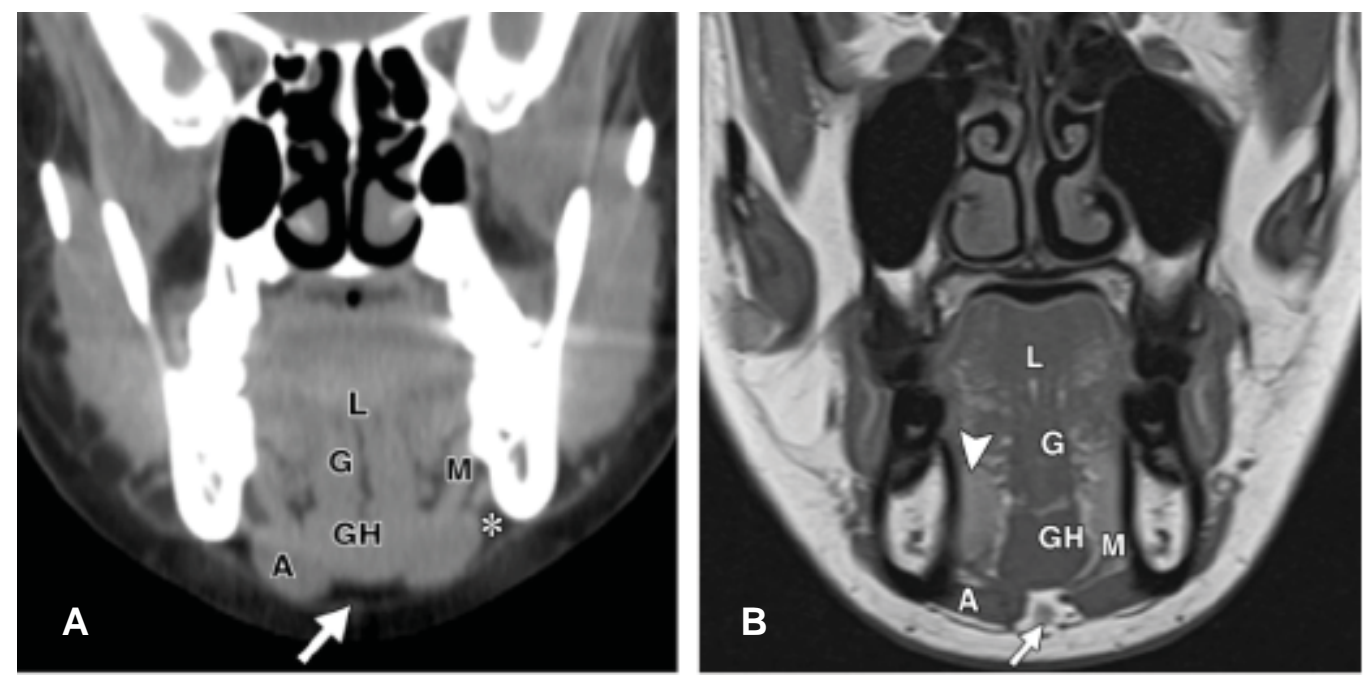

Figura 1. Anatomía normal del piso de la boca. Las imágenes coronales obtenidas con tomografía computarizada (TEM) (a) y resonancia magnética T1 (IRM) (b) muestran una apariencia normal de la cara anterior del piso de la boca: el septo lingual de la línea media (L); el complejo muscular geniogloso $(\mathrm{G})$ y geniohioideo $(\mathrm{GH})$; el músculo milohioideo (M), que separa el suelo de la boca de los espacios submentoniano (flecha) y submandibular (*) y el músculo digástrico anterior (A); y las glándulas sublinguales (punta de flecha en b) (2) 

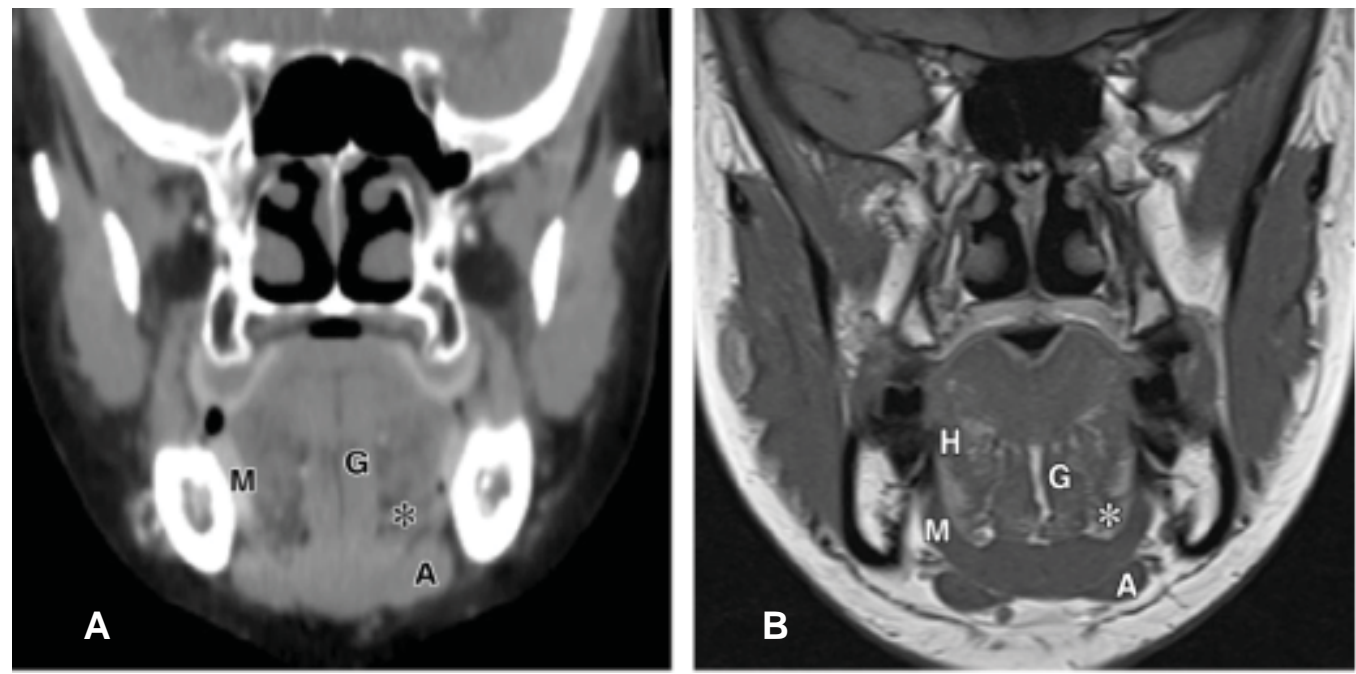

Figura 2. Imágenes de TEM coronal (a) y IRM (b) ponderadas en T1 en el medio del piso de la boca muestran el espacio sublingual (*) como un plano con baja atenuación en la TC y alta intensidad de señal en la RM. El plano es medial al músculo milohioideo (M) y contiene el músculo hiogloso $(\mathrm{H})$. $\mathrm{A}$ = músculo digástrico anterior, $\mathrm{G}=$ músculo geniogloso (2).
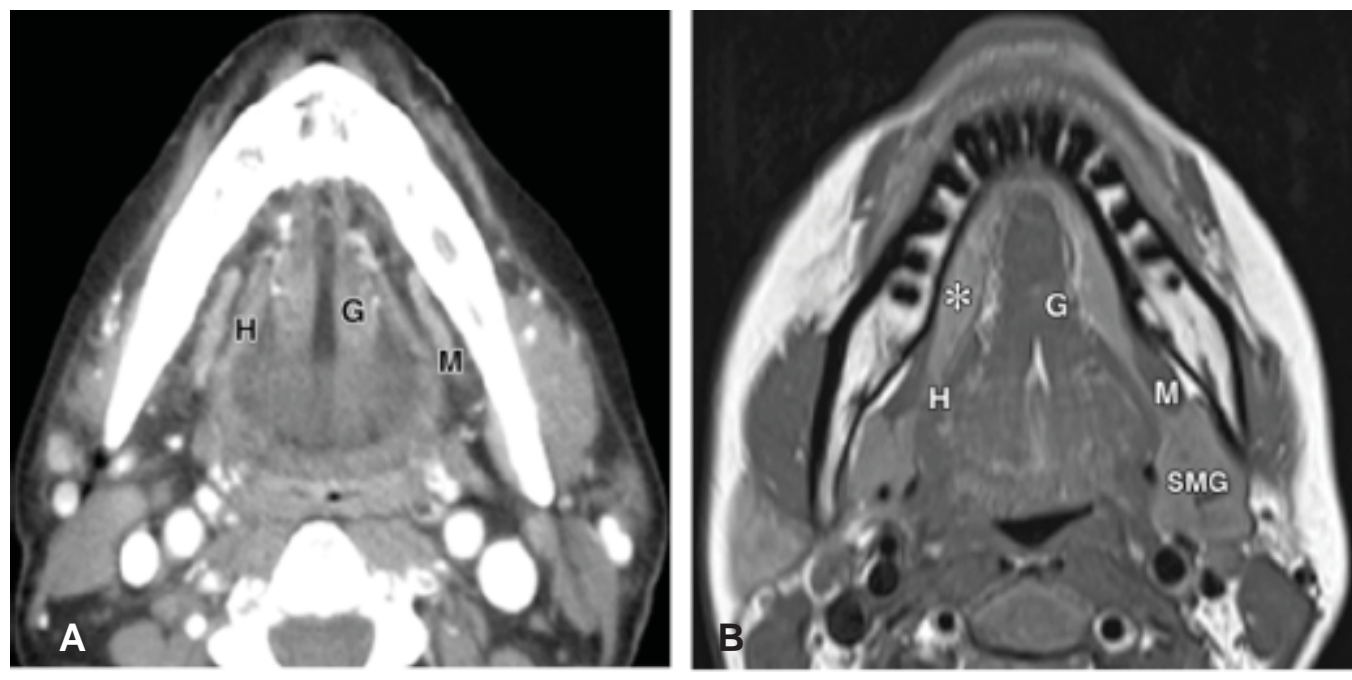

Figura 3. Las imágenes axiales de TEM (a) y IRM (b) ponderadas en T2 muestran los músculos geniogloso (G) e hiogloso lateral (H) y milohioideo (M) en la línea media. El aspecto profundo de la glándula submandibular (SMG) se extiende hacia la porción posterior del espacio sublingual, que también contiene las glándulas sublinguales (* en b) anteriormente (2). 

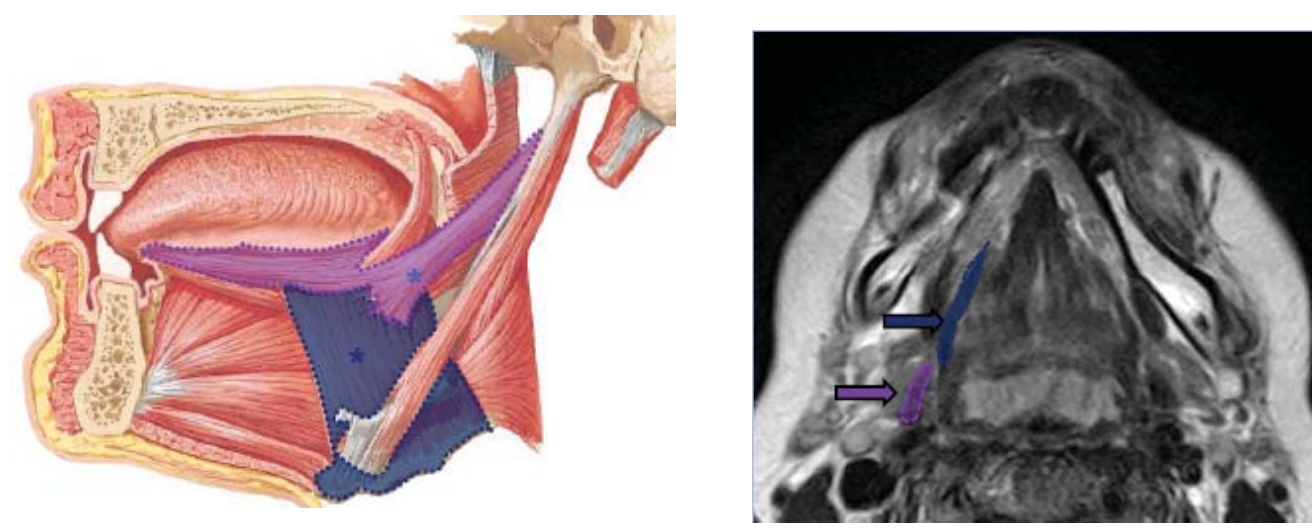

Figura 4. Espacio sublingual, Músculos hioglosos (*azul), Músculos estiloglosos (*lila) (1).
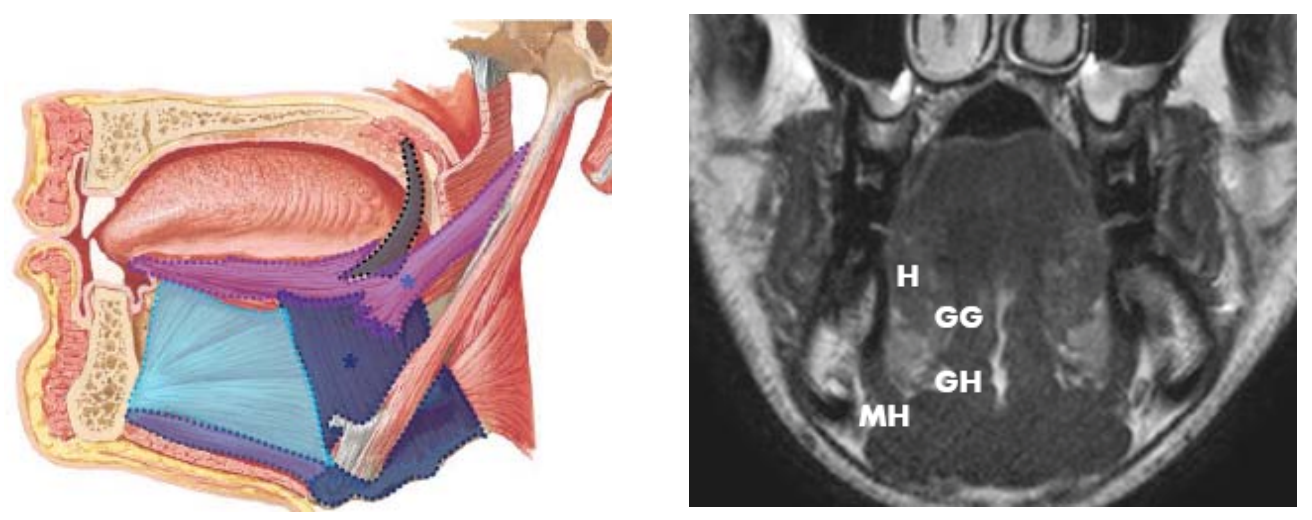

Figura 5. Musculatura extrínseca, musculos geniogloso-genihiodeo (GG), musculo hiogloso (H), musculo genihioideo $(\mathrm{GH})$, musculo miohioideo (MH) (1). 

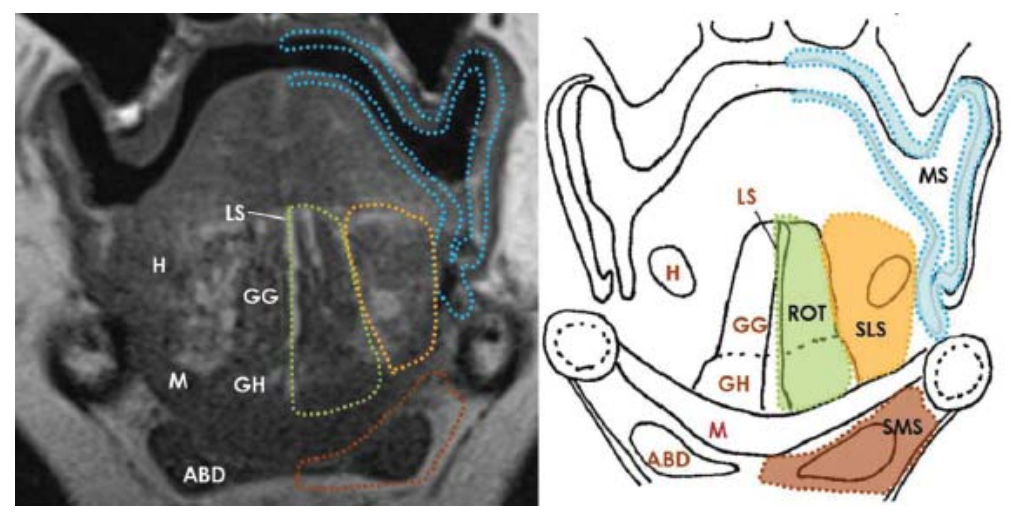

Figura 6. Estructuras y espacios normales de la cavidad bucal en la RM coronal potenciada en T1 con diagrama esquemático. M, músculo milohioideo; $\mathrm{ABD}$, vientre anterior del músculo digástrico; $\mathrm{H}$, músculo hyoglossus; $\mathrm{GH}$, músculo geniohioideo; GG, músculo geniogloso; LS, tabique lingual; SLS, espacio sublingual (naranja); SMS, espacio submandibular (marrón); ROT, raíz de la lengua (verde); y MS, espacio de la mucosa (azul)(6).

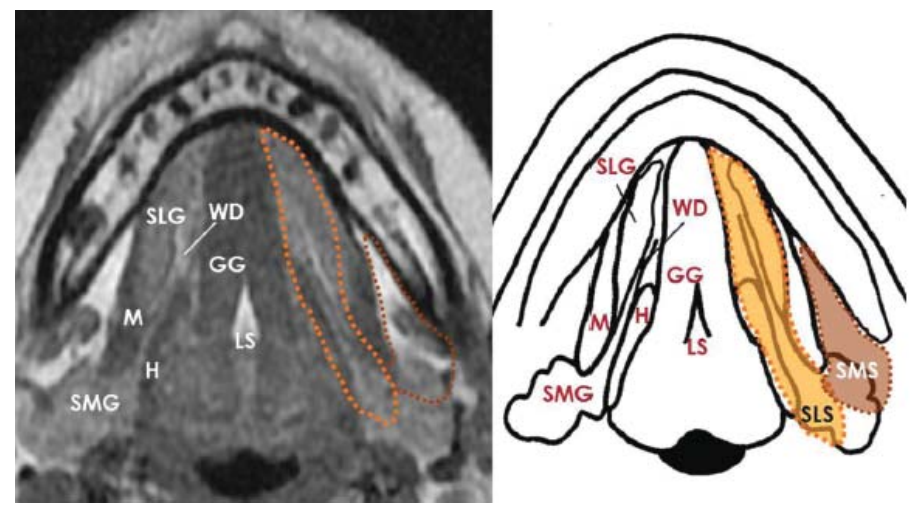

Figura 7. Estructuras y espacios normales de la cavidad bucal (a nivel del piso de la boca) en RM axiales T1 con diagrama esquemático. SLG, glándula sublingual; SMG, glándula submandibular; M, músculo milohioideo; H, músculo hyoglossus; GG, músculo geniogloso; LS, tabique lingual; WD, conducto de Wharton; SLS, espacio sublingual (naranja); SMS, espacio submandibular (marrón) (6).

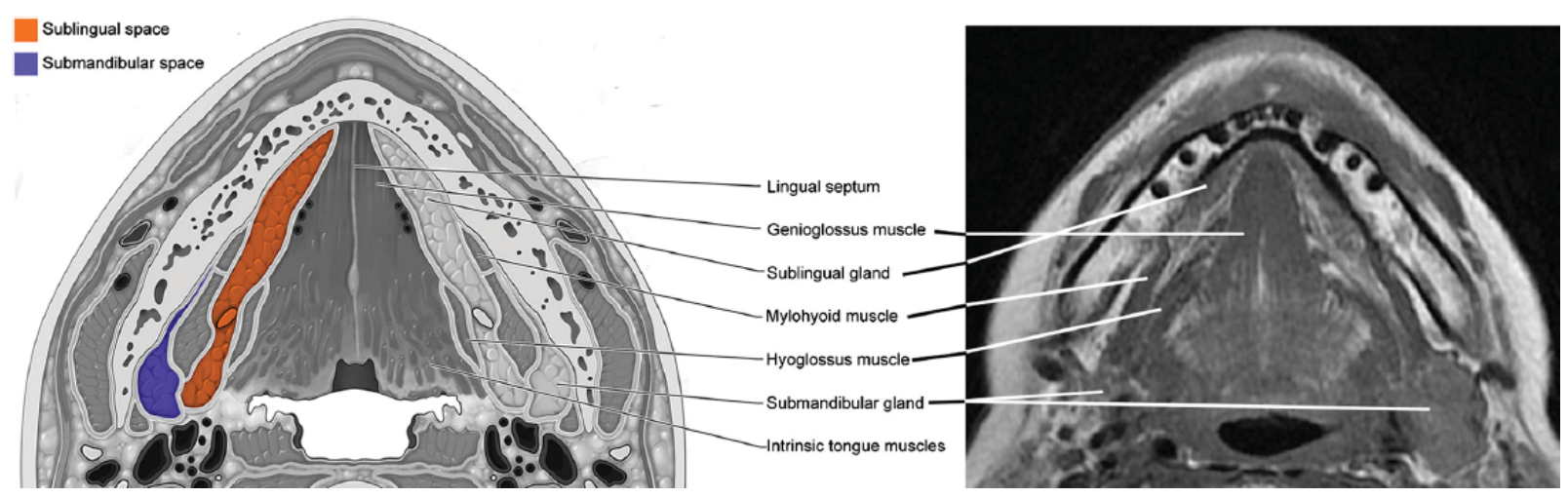

Figura 8. Anatomía de los espacios submandibular y sublingual en el plano axial: ilustración de la imagen e imagen de RM ponderada en T1. Tomadas de: Patel S, Bhatt AA. Imaging of the sublingual and submandibular spaces. Insights Imaging. 2018 Jun;9(3):391-401.(7) 


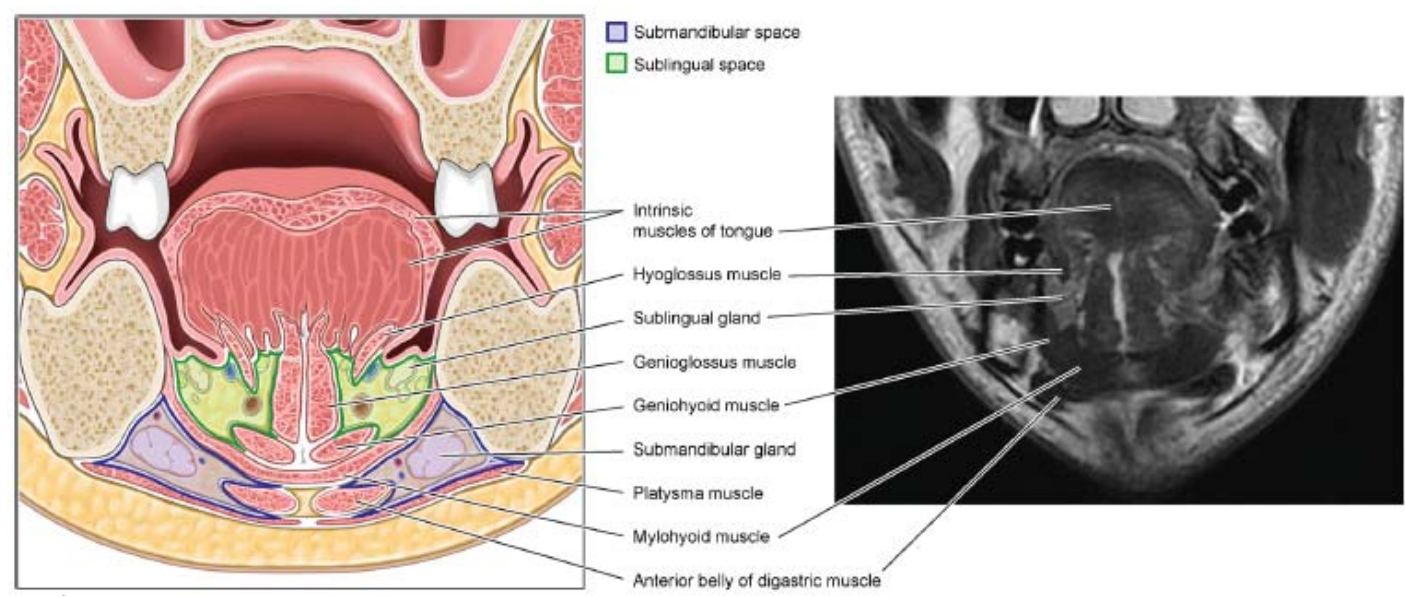

Figura 9. Anatomía de los espacios submandibular y sublingual en el plano coronal: ilustración de la imagen e imagen de RM ponderada en T2. (7).

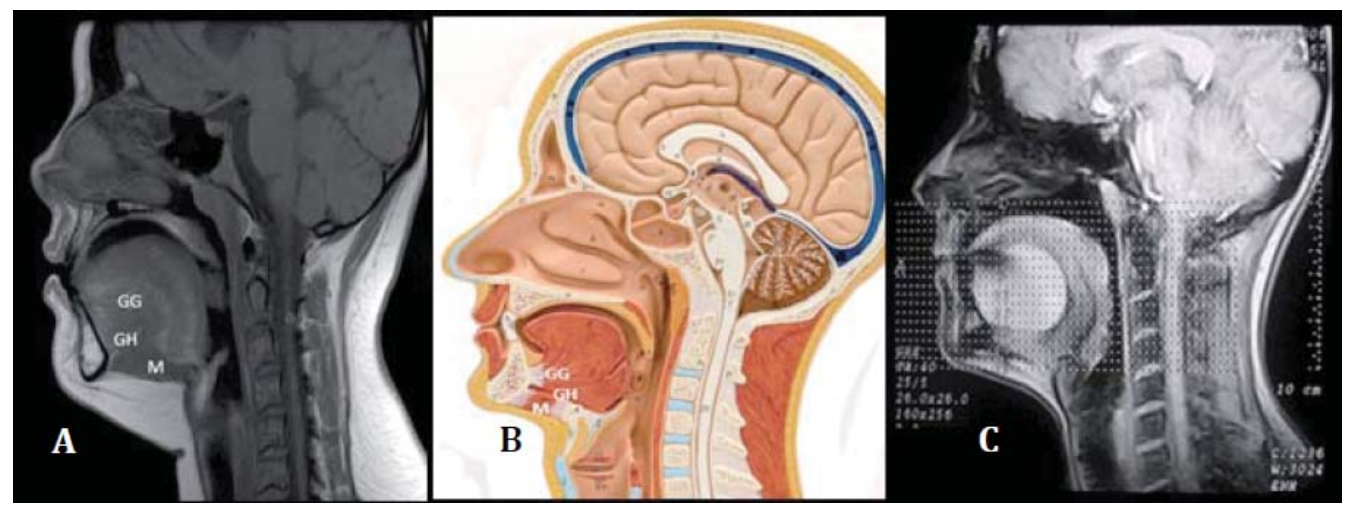

Figura 10. RM en T1 corte sagital que muestra el músculo geniogloso (GG), genihioideo (GH) y milohioideo (M). Tomado de: Sempere Durá T. Atlas de anatomía por la imagen seccional [CD-ROM]. Primera Edición. Barcelona: Editorial Química Farmacéutica Bayer; 2009. B. Ilustración del piso de boca. Tomado de: Chiapasco M. Procedimientos de cirugía oral respetando la anatomía. Caracas: Editorial Amolca; 2009. C. Imagen hiperintensa ovoide de límites defi nidos localizada en el piso de boca (4).
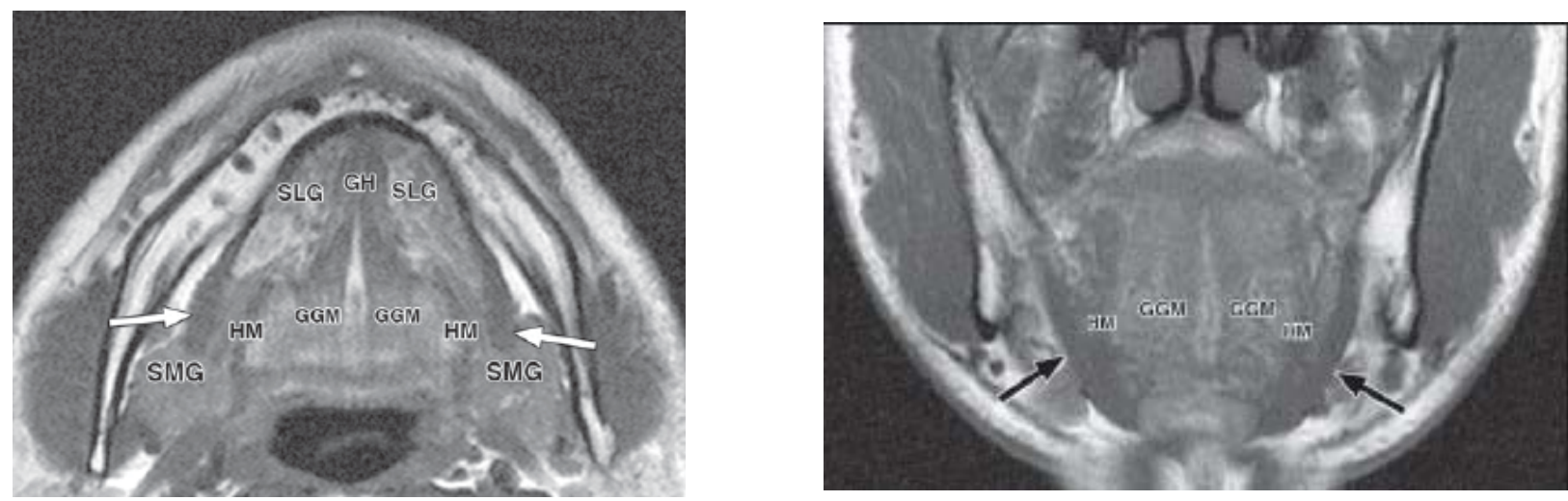

Figura 11. Anatomía MR del músculo milohioideo. SLG = glándula sublingual, $\mathrm{SMG}=$ glándula submandibular, $\mathrm{HM}=$ músculo hiogloso, $\mathrm{GH}=$ músculo geniohioideo, $\mathrm{ABD}=$ vientre anterior del músculo digástrico, GGM = músculo geniogloso. A, las imágenes axiales de RM de alta resolución muestran el músculo milohioideo (flechas) en cada corte. B, honda de músculo milohioideo (flechas) se delinea bien en las imágenes coronales de RM de alta resolución (10). 


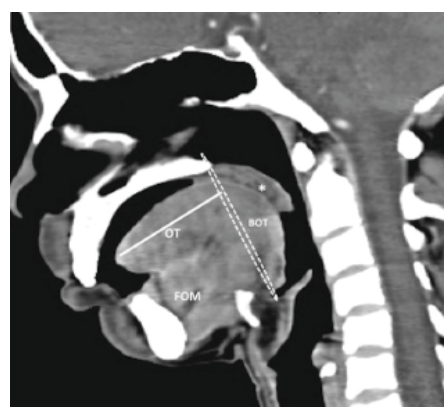

Figura 12. Reforma sagital en la sección 16 TCMD muestra el límite entre la cavidad oral y la orofaringe como una línea circular que se extiende desde la unión del paladar duro y el paladar blando (*) a lo largo de cada pilar tonsilar anterior hasta el dorso de la lengua en la región de papilas circunvaladas (no se ve en imágenes). BOT, base de la lengua; OT, lengua oral (la extensión se muestra por línea horizontal); FOM, piso de la boca (13).

\section{DISCUSIÓN}

\section{Posibilidades de hacer una evaluación de músculos del piso de boca con TEM}

La TC es particularmente útil para evaluar los procesos inflamatorios agudos porque es capaz de representar la erosión y destrucción del hueso cortical mandibular, el cambio cutáneo y los cálculos del conducto submandibular. Sin embargo, se puede identificar con algo de detalle los músculos del piso de la boca, esta puede ser una ventaja diagnostica ya que es más económica en comparación con una IRM $(8,9,10)$.

La IRM proporciona una mayor resolución de los tejidos blandos que la TEM, y es particularmente útil para identificar tumores malignos de la cavidad oral que afectan al piso de la boca y procesos complejos de enfermedades que se extienden a través de múltiples espacios anatómicos, la diseminación perineural de los tumores se representa mejor mediante la RM que con la TC $(11,12,13)$.

Las limitaciones de la IRM del piso de la boca incluyen artefactos producidos por el movimiento relacionado con la deglución y por la amalgama dental metálica. Desafortunadamente, los artefactos de la amalgama dental pueden distorsionar las imágenes de TEM e IRM del piso de la boca y oscurecer detalles importantes $(14,15)$.

La inspección física simultánea del piso de la boca es posible y puede ayudar en el diagnóstico.

\section{CONCLUSIONES}

Es necesario comprender los aspectos radiológicos en el piso de la boca y los puntos de referencia anatómicos de la región, el estudio imagenológico ideal para esto es la resonancia magnética sin embargo en la tomografía espiral multicorte es posible identificarlos con una menor resolución y debe ser complementada con un dominio de las estructuras anatómicas de la región.

\section{Correspondencia:}

Kevin Roberto Romero Díaz

Correo electrónico: kevin.romero@upch.pe

\section{REFERENCIAS BIBLIOGRÁFICAS}

1. Mendivil A. Anatomia radiologica de la faringe y cavidad oral. Madrid: Sociedad Española de Radiologia: 2016.

2. La'porte SJ, Juttla JK, Lingam RK. Imaging the floor of the mouth and the sublingual space. Radiographics. 2011; 31(5):1215-30.

3. Huarcaya MQ, Gaspar AS. Evaluación anatómica del piso de boca mediante resonancia magnética. 2015;25(4):309-17.

4. Santana L, Ferreira A, Martins C, Faria R, Carvalho A, Francisco de Mendonza E. Epidermoid cyst: highlights on diagnosis and magnetic resonance imaging features. Rev odonto ciência. 2010; 25(2):204-7.

5. Ruiz-Imbert AC, Calderón-Ubaqui V, DelgadoAzañero WA, et al. Evaluación mediante radiología, tomografía computarizada y resonancia magnética de 
un ameloblastoma sólido. Reporte de un caso. Rev estomatol Hered. 2014;24(3):178-85.

6. Law P, Chandra R, Hoang J, Phal P. Imaging the oral cavity: key concepts for the radiologist. The British Journal of Radiology. 2011;84(1006):944-57.

7. Patel S, Bhatt AA. Imaging of the sublingual and submandibular spaces. Insights Imaging. 2018; 9(3):391-401.

8. Bjork MB, Kvaal SI. CT and MR imaging used in age estimation: a systematic review. JFOS -Journal Forensic Odonto-Stomatology. 2018;36(1):14-25.

9. Schmutz B, Rahmel B, McNamara Z, Coulthard A, Schuetz M, Lynham A. Magnetic resonance imaging: An accurate, radiation-free, alternative to computed tomography for the primary imaging and threedimensional reconstruction of the bony orbit. J Oral Maxillofac Surg. 2014;72(3):611-8. doi: 10.1016/j. joms.2013.08.030

10. Otonari-Yamamoto M, Nakajima K, Tsuji Y, et al. Imaging of the mylohyoid muscle: separation of submandibular and sublingual spaces. AJR Am J Roentgenol. 2010; 194(5):W431-8. doi: 10.2214/ AJR.09.3516
11. Puricelli E, Ottoni B, Silva A, Ponzoni D. Occurence of dermoid cyst in the FOM - the importance of differential diagnosis in pediatric patients. J Appl Oral Sci. 2017 ; 25(3): 341-345. doi: 10.1590/1678-77572016-0411

12. Meesa IR, Srinivasan A. Imaging of the oral cavity. Radiol Clin North Am. Elsevier Inc; 2015;53(1):99-114.

13. Arya S, Rane P, Deshmukh A. Oral cavity squamous cell carcinoma: Role of pretreatment imaging and its influence on management. Clin Radiol. 2014; 69(9):916-30. doi: 10.1016/j.crad.2014.04.013

14. Kato H, Kawaguchi M, Ando T, Mizuta K, Aoki M, Matsuo M. Pleomorphic adenoma of salivary glands: common and uncommon CT and MR imaging features. Jpn J Radiol. 2018;36(8):463-471. doi: 10.1007/s11604-018-0747-y

15. Giarraputo L, Savastano S, D'Amore E, Baciliero U. Dermoid cyst of the floor of the mouth: Diagnostic Imaging Findings. Cureus. 2018;10(4):e2403. doi: 10.7759/cureus.2403.

Recibido: 13-07-2018

Aceptado: 20-01-2019 